\title{
The Concept and Its Practice of Western Music History
}

\author{
Mei $\mathbf{W u}^{1}$ \\ ${ }^{1}$ Shaanxi Xueqian Normal University, Xi’an, Shaanxi, 710000
}

Keywords: concept and practice; Western Music history; education

\begin{abstract}
Musical history is the study of examining and reflecting on the history of music. Examining, understanding and expression of the historical development of music and forming a historical perspective with the integration of music studies has become the main approach for us to explore the implication of music history and its significance. Western music historiography is a kind of science with special horizons and independent domains that is integrated into historical musicology.
\end{abstract}

\section{Introduction}

Music historiography is not an independent discipline. It is a kind of science with special horizons and independent domains that is integrated into historical musicology. From a methodological point of view, the "rethinking" demonstrated by music historiography during the study of the history of music actually reflects the reflection on the ontological meaning of history. This kind of music history with inquiry characteristics determines the construction of music and determines the history of music. Independent status and specific academic significance in the overall discipline structure of musicology. Therefore, Western music historiography and historical musicology are two special areas that are both distinct and closely related: The overall academic scope of historical musicology includes the study of Western music historiography, while the knowledge and the discourse of Western music history are directly It was born in the "matrix" of historical musicology and promoted the development of historical musicology with the unique academic discourse of history. Undoubtedly, exploring the development of western music historiography will enable us to understand the Western music academic tradition and contemporary trends at a higher level, and deepen our thinking and understanding of the historical process of western music.

Although Western thinkers, philosophers, music theorists, composers, and other intellectuals from the ancient Greeks were happy to talk about music theory and have a tradition of writing about music, as a knowledge inquiry with modern academic meaning, Western music history was formed in the 18th century. This is a great era of loving knowledge, advocating rationality and pursuing humanistic spirit. The rise of the Enlightenment not only rapidly promoted the transformation of Western societies, but also strongly promoted the development of Western knowledge; Encyclopaedia's thinkers profoundly influenced their open minds and their ambitions and dedication to the construction of academic careers. At that time, scholars in various fields of the humanities discipline. Rationalism, as a kind of thought that pervades Europe, has a guiding role in the exploration of various knowledge. There is no doubt that the formation of Western music historiography is closely related to the rationalist trend of thought during the Enlightenment period: as with the construction of other studies in this era, the use of rational methods (clear lines of thought and logically narrated narratives) reflect on and explain the development of music. The process became the basic way for Western music historians to begin research in the early 18th century. Therefore, Western music historiography has already possessed a rationalistic academic character at the beginning of its birth. Influenced by the grand vision of the encyclopaedia school, which focuses on the integration of knowledge, 18th-century music historians are also trying to explore and include all the musical knowledge that can be obtained, and to show the progress of the music through the combing and examination of "system" and "science". . It is worth noting that in the 18th century writings on music, evolutionary ideas occupied a dominant position: the 
development of music arts was regarded as an evolutionary process from low-level to high-level, from simple to complex, and became the majority of scholars at the time. consensus. Therefore, musicologists in this period naturally regard 18th-century music as the best music. It should also be pointed out that 18th century music historians and other musicologists have noticed the existence of non-European musical traditions. They are concerned about the phenomenon of so-called "folk" and "primitive" music, such as the encyclopedic French thinker and musician Jacques Rousseau (1712 1778) in his "Music Dictionary". Mentioned non-European music culture like American Indian music. 2 However, in the 18th century Western music writing, there can be no ethnomusicology and vision. In the eyes of Western music scholars in the 18th century, non-European music was not an equal "exotic culture". Their contempt for and mention of these musical phenomena was just "authentic" under the guidance of the "European Cultural Center Theory". "European music research adds an "academic embellishment."

\section{Western Music History Concept}

Looking at the history of Western music in the 20th century, the breadth and depth of academic research and the speed with which academic achievements accumulate are incommensurable in the past. If we classify music history into the system of historical musicology and examine academic progress from this system, then the situation in the early to mid 20th century was: a continuous stream of academic achievements-monographs, collections, doctoral dissertations, and works. And academic commentary editions (criticaleditions, etc.) have pushed the "learning" of Western musical history to an unprecedented height. It is worth noting that the study of the history of music in this period did not result in a new "history" of music history at the same time as the "big harvest". In other words, Western traditional positivism still dominates the direction of the development of music historiography. Almost all scholars in the field of historical musicology are tirelessly engaged in the combing of historical facts, textual research, and interpretation of literature.

The influence of the positivist tradition has spread throughout the Western history of musicology, including, of course, American historical music that directly benefited from European culture and scholarship. In the middle of the 20th century, a group of distinguished scholars who moved to Europe from the United States began teaching at some prestigious universities in the United States. 27 In a quiet university campus and excellent academic environment in the United States, these scholars have not only achieved many new results in their personal research, but also the academic ideas and methods delivered by their research and teaching are rapidly growing toward American musicology. Played a vital role. Therefore, the development of American historical musicology-music historiography carries the European academic tradition. Norton Press 28 began editing and publishing "The Norton History of Music" in the mid-20th century. The authors were all outstanding scholars who were active in American music studies at that time. Therefore, each of the works on the history of music dating from their writings has become an "authoritative text" in these fields. From the current point of view, although the literature, history, and viewpoints of these works may be somewhat out of date, this does not affect their significance as a "classic" because of the broad academic vision that this series of musical history demonstrates. Yanzheng's attitude to history and the discourse of historiographical history lay a paradigm for the modern narrative of the history of Western music. 29 The most influential of this series is "Gustave Reese (1899 - 1977)" Medieval Music and Renaissance Music. Rees, with his excellent academic understanding and literature summary ability, freely integrates the rich and unusual academic achievements of the two researches on the history of broken generations, while presenting the academic traditions of related topics, he also proposes his own historical evolution of Middle Ages and Renaissance music. the opinion of. The two musical historical works of Reese not only had a great influence on the research of later generation history, but also played a significant role in the American music field's gradual establishment of advantages in the early music research field. The rise of research and writing in the history of music has further driven the development of music thematic history. The history of music in the field of musicology is a historical investigation of a particular music theme. Compared with the history of music and the history of music, the scope of the study of music thematic history is 
more open, and the space for academic exploration is naturally wider and deeper. The special historical masterpieces born in the middle of the 20th century became the most academically valuable achievements in the study of music history in this period. Its pioneering academic significance has always influenced the study of contemporary scholars-Sams (CurtSachs, 1881 1959). The History of Musical Instruments, 30 The Epic of Italy by Alfred Einstein (1880-1952) and The Holy Grigori of Willi Apel (1893-1988) and before 1700 The History of the Keyboard Music is recognized as a pioneering work in these specialized fields, laying a very solid academic foundation for the continued research of contemporary scholars. It can be said that the successive publication of these music monographs has marked the study of western music history has entered a new world. The decline of the general history of music writing and the continuous rise of the history of broken history and monographs show that: under the influence of positivism, the western music historiography has increasingly tended to meticulous and specialized academic inquiry, reflecting a research result. High quality "academic content" respected and pursued.

\section{New Musicology Theory and Practice}

The "New Musicology" that emerged in the 1990s is an academic power that cannot be ignored in the field of contemporary Western musicology. Its influence on the development of contemporary western music history cannot be underestimated. 41 In 2005, Richard Taruskin (1945 ), a professor of music studies at the University of California at Berkeley, one of the leading figures in "New Musicology," dedicated to the world his 13 years of hard work in music history. The "Oxford Western Music History" (a total of six volumes, all over 4,000 pages) immediately attracted the attention of the western music field. 42 This is the first comprehensive history of Western music written by a scholar after Ambrose. Taruszky's challenge to the tradition of Western musical history is not only personal academic courage and creative talent. 43 - It tells the world that the individual's ability to independently narrate the overall historical evolution of Western music and its academic value still exist - - More importantly, it infiltrates the book's reflective spirit and critical consciousness. Although the author's research is still based on the history of musical division history that has reached a consensus in the western academic circles, the narrative channel number and sub-volume design of the book have already broken through the basic structure of the "six generations and six volumes" of the routine. Taruschi's attention to the various music ages, the focus of discussion, and the proportion of content are completely beyond people's imagination: about $40 \%$ of the space contributed to 20th century music. This is a highly personal music history book. The selection of the characters, events, phenomena and works in the history of music and their discussion completely follow the author's own academic path. He wanted to tell the readers that this is no longer a "musical history overview" or "musical history description" that was formed in the traditional sense solely on the basis of historical facts, literature presentations and explanations, but rather a presentation issue and introspection of the West. The academic tradition of "the history of music". Here, the author emphasizes that not only composers and works of art, but also the process of production or production of works, the social and political context of music, and the changing acceptance of musical arts are all essential elements in constructing "meaning" of music. In this musical history, Taruszky examined the issues that he believes affect the historical process of Western music by using the attitude of cultural studies and the critical examination of the characteristics of "new musicology." In the overall domain of this book, the interdependence between "pure music" and "title music", the interaction between oral traditions and folk traditions and art music, the power of mythology, and the possibility of "meaning" of music become Tarus The core content of the music history discourse. Many of the ideas Taluski has demonstrated have challenges to the tradition of historical musicology, so this "latest" musical history has also caused much controversy. However, the author's academic attitude and writing practice that dare to challenge the tradition of music history may be the unique value of the music's general history text - the presentation of the contemporary western music history has been completed from the "Historical materials-history-history theory From the "paradigm of history - critical interpretation" paradigm shift. In such a history of music, we can strongly feel the "academic originality" of the 
author's integration into his own cultural understanding and ideal pursuit. Taruszky's book on the history of Western music fully embodies the basic trend of contemporary western music historiography: reconstructing the history of western music with a spirit of reflection; rethinking the concepts and traditions of western music historiography with a sense of criticism; with culture The appeal re-examined the value and significance of the music world.

\section{Conclusion}

Western music historiography has been integrated into history musicology more deeply and "freely" because the "researchability analysis" and "criticism interpretation" reflected by the research institutes in many fields of contemporary historical musicology are traditional Western. The Institute of Music History is inconceivable. Therefore, this kind of reflective knowledge points to the logical progression of the "academic context" that is inherent in Western music history and historical musicology. It can be foreseen that with the expansion of the academic vision and the deepening of the understanding of the human music culture, the research directions of the western music historiography and the knowledge itself will face new challenges. The continuation of the music academic tradition must be accompanied by changes that reflect the spirit of the times.

\section{References}

[1] Gao Shijie. A New Interpretation of "Reviving Spirits in the West"-Sequentially followed by Cai Zhongde [J]. Symphony - Journal of Xi'an Conservatory of Music. 2010 (03)

[2] Ye Songrong. The Feasibility Study of "China's Perspective" in the Study of Western Music History - Enlightenment from Cross-reference with Other Subjects [J]. Music Research. 2010 (05)

[3] Heinrich Geiger, Liu Jingshu. "Flourishing - Classical Western Music in China" [J]. Journal of Central Conservatory of Music. 2010 (03)

[4] Gong Hongyu. Christian missionaries and the creation of Chinese school music education (below) [J]. Music Research. 2007 (02)

[5] Gong Hongyu. From Ricci to Li Delun - Western classical music in China [J]. Chinese Musicology. 2006 (04) 